\title{
CORRECTION
}

Open Access

\section{Correction to: The mTOR inhibitor rapamycin down-regulates the expression of the ubiquitin ligase subunit Skp2 in breast cancer cells}

\author{
Ma'anit Shapira ${ }^{1,2}$, Eli Kakiashvili ${ }^{3}$, Tzur Rosenberg ${ }^{2}$ and Dan D. Hershko ${ }^{1,2,4^{*}}$
}

\section{Correction}

After the publication of this work [1], an error was noticed in Fig. 2b, Fig. 3a and Fig. 5b. The Skp1 loading control was accidentally duplicated. We apologize for this error, which did not affect any of the interpretations or conclusions of the article.

\section{Author details}

'Department of Surgery A, Rambam Medical Center, 31096 Haifa, Israel.

${ }^{2}$ Technion - Israel Institute of Technology, 31096 Haifa, Israel. ${ }^{3}$ Department of

Surgery B, Rambam Medical Center, 31096 Haifa, Israel. ${ }^{4}$ Breast Health

Institute, Rambam Medical Center, 31096 Haifa, Israel.

Received: 29 May 2018 Accepted: 29 May 2018

Published online: 09 July 2018

\section{Reference}

1. Hershko D, et al. The mTOR inhibitor rapamycin down-regulates the expression of the ubiquitin ligase subunit Skp2 in breast cancer cells. Breast Cancer Res. 2006;8(4):R46.

\footnotetext{
* Correspondence: d_hershko@rambam.health.gov.il

'Department of Surgery A, Rambam Medical Center, 31096 Haifa, Israel

${ }^{2}$ Technion - Israel Institute of Technology, 31096 Haifa, Israel
} 